\title{
Elementos para uma integração Micro-macrodinâmica na Teoria do Desenvolvimento Econômico*
}

\author{
M ario Luiz Possas
}

Professor do Instituto de Economia da UFRJ.

\section{ABSTRACT}

The purpose of this essay is to suggest a mix of $\mathrm{N}$ eo-Schumpeterian and Post-K eynesian elements that might turn possiblean integration of micro and macro dynamical features, 50 as to support a non-orthodox reconstruction of theT heory of Economic D evelopment. M utually compatibletheoretical issues areacknowledged and briefly discussed, such as uncertainty ("hard" or "fundamental") and structural instability (without equilibrium), on thestructural side, aswell as behavioural onessuch as bounded or procedural rationality. Theevolutionary $\mathrm{N}$ eo-Schumpeterian approach for the dynamics of firms and markets is shortly reviewed, followed by some wellknown dynamic propertiesstemming from the principle of effectivedemand, of Kaleckian and Keynesian origin - e.g. multiplier and accelerator effects, among others. It is argued that their integration may provide the basis for a dynamic theory in which micro and macro analytical levelsblend naturally. Such integration will certainly requirea disaggregate, multisectoral dynamic analysis and instruments. In addition, simulation models should beemployed, given theabsence of equilibrium assumptionstogether with thepresence of stochastic variables at themicro level, related to evolutionary processes, especially those of innovativeand competitivecontent.

KEYWords I Theory of Economic D evelopment; M acroeconomic D ynamics; M ultisectoral Analysis.

JEL-C Odes | 011 - M acroeconomic Analysis of Economic D evelopment; 041 - M ultisectoral Growth M odels. 


\section{RESUMO}

0 artigo propõe uma combinação de elementosneo-schumpeterianose pós-keynesianos quetornam possivel umaintegração quepoderia servir debasea umareconstrução não-ortodoxa daTeoria do D esenvolvimento Econômico. Como fundamentosteóricos mutuamentecompatíveis são identificados ebrevementediscutidos pressupostos estruturais como incerteza ("forte" ou "fundamental") e instabilidade estrutural (sem equilíbrio), bem como pressupostos comportamentais como racionali dadelimitada ou processual. Em seguida, são expostas as bases evolucionárias neo-schumpeterianas de uma abordagem microdinâmica das firmas e dos mercados que, conjugada aos resultados dinâmicos associados ao princípio da demanda efetiva, de origem kaleckiana ekeynesiana - efeitos detipo multiplicador eacelerador -, proporciona uma teoria dinâmica em queosníveis micro emacro seintegram naturalmente. Ao nível analítico, este tipo de integração requer um tratamento multissetorial, enão agregado, para a macrodinâmica. Além disso, devem ser empregados modelos de simulação, dada a ausência de pressupostos de equilíbrio ea presença decomponentes estocásticos no âmbito microeconômico, associados aos processos evolucionários, especial menteos detipo inovativo ecompetitivo.

Palavras-chave | Teoria do D esenvolvimento Econômico; D inâmicas M acroeconômicas; Análise M ultissetorial.

CódigosJEL | 011 - AnáliseM acroeconômica do D esenvolvimento Econômico; 041 M odel os deC rescimento M ultissetorial.

\section{Introdução}

Embora passível demuitas críticas, éinegável quea “N ova Economia do D esenvolvimento" (doravanteN ED) desenvolvida pelo mainstream da ciência econômica desde o final dos anos 1980 trouxe ao debate sobre 0 desenvolvimento pelo menos al gunstemas relevantes, que, a meu ver, merecem ser retomados desde uma perspectiva não-ortodoxa: (i) a própria recolocação da questão do desenvolvimento, não só por meio de exaustivas comparações empíricas internacionais, mas enquadrada em termos de teoria econômica, o que havia sido praticamente abandonado desde os anos 1960; (ii) a busca de microfundamentos - embora os que ela utiliza sejam muito discutíveis - das traj etórias de crescimento/desenvolvimento, o queera praticamente ausente da 
tradição anterior da economia do desenvolvimento, com exceção de al gumas contribuições mais recentes de extração schumpeteriana; e(iii) a preocupação, ainda que freqüentemente enquadrada de modo superficial, com os fatores endógenos do desenvolvimento, destacando-se o progresso técnico ea presença de retornos crescentes a ele relacionados, o que tem aberto uma perspectiva de diálogo com a tradição schumpeteriana.

Entretanto, as profundas diferenças em termos de opções teóricas e metodológicas da abordagem do mainstream vis-à-vis as abordagens evolucionária/neo-schumpeteriana e keynesiana - por nós consideradas as referências teóricas fundamentais para uma construção alternativa - tornam inviável, mesmo a partir de al guns pontos de contato, qual quer tentativa de "esforço conjunto", exigindo, ao contrário, uma demarcação clara das divergências e das razões desta irredutibilidade. $\mathrm{N}$ a tradição de Schumpeter - mencionado várias vezes mas pouco utilizado adequadamente pela NED -, bem como de Keynesedosmodelosneo-keynesianos, a teoria do desenvolvimento econômico deve estar baseada não em pressupostos de equilíbrio (ainda que "dinâmico"), mas em decisões dos agentes, especialmente de investir, que - por sua vez desencadeiam efeitos dinâmicos cumulativos de desajustee de expansão.

Consideramosquea correnteneo-schumpeteriana, especialmenteem sua vertente evolucionária, forma com a pós-keynesiana (bem como a neokeynesiana, mais antiga) - não obstante suas diferenças reais ou aparentes - a principal referência teórico-metodológica para uma teoria econômica do desenvolvimento fora do mainstream, como já ressaltado em artigo anterior. ${ }^{1}$

Como visto então, o principal terreno comum, queao mesmo tempo as distingue teoricamente do mainstream, éa rejeição de dois pressupostosteóricometodológicos neoclássicos fundamentais, sobre os quais se constroem quase todos os programas de pesquisa vinculados ao mainstream: o princípio da raci onalidadesubstantiva (maximizadora), mesmo sob informação incompleta eincerteza "forte"; eo do equilíbrio deagentes emercados. Embora obviamente não restritos às teorias do crescimento e desenvolvimento, tais pressupostos tornam-seainda mais problemáticos nestasúltimas, devido à maior dificuldade

\footnotetext{
Ibidem. A corrente neo-institucionalista, embora possua grande margem de compatibilidade e muitos pontos de contato, não se caracteriza especificamente por aportes significativos de natureza teórica, e por isso não será objeto de revisão neste texto.
} 
teórica e empírica de conciliar seu conteúdo e suas implicações fortemente estáticas com o caráter dinâmico do objeto detais teorias.

É objetivo do presente ensaio indicar as linhas de maior potencial dessas correntes, em termos de aporte teórico passível de integração, para uma teoria al ternativa do crescimento e do desenvolvimento econômicos, a partir deuma revisão de suas principais contribuições não apenas para esta literatura específica, mas em particular para os correspondentes fundamentos teóricos. A próxima seção elabora o terreno teórico-metodológico comum eas principais diretrizes para uma teoria alternativa que daí emergem. A seção 3 reconstitui brevemente as contribuições da literatura pós-keynesiana, não diretamente relacionada ao tema central, mas que oferece aportes relevantes a uma teoria geral do investimento, crucial em teorias emodelos dinâmicos, assim como da vertente chamada neo-keynesiana, mais antiga (principalmenteos modelostradicionais, incluindo o de K alecki). A seção 4 reconstitui as contribuições da literatura neo-schumpeteriana/ evolucionária, não só as mais específicas ao tema - seus modelos recentes de crescimento edesenvolvimento - , como também as análises e modelos de recorte microdinâmico, discutindo seus microfundamentos e potencial deintegração com o nível macro. A quinta eúltima seção propõe, em linhas ainda preliminares, um esquema analítico que integre essas diferentes contribuições numa perspectiva micro-macrodinâmica, essencial para tratar o crescimento e o desenvolvimento econômicos num enfoque alternativo que não apenas seja consistente em termos teóricos, mas que tenha potencial de aplicação analítica emodelística. Segue-seuma breveconclusão, apontando para osprincipais desafios.

\section{Pressupostos teóricos comuns: racionalidade, incerteza e instabilidade}

D o ponto de vista metodológico, em primeiro lugar, à diferença dos pressupostos adotados nos model os da N ED , os pressupostos correspondentes nos enfoques tanto evolucionário/neo-schumpeteriano quanto (neo- e pós-) keynesiano não assumem o equilíbrio como norma; ao contrário, extraem implicações dinâmicas relevantes da presença de desequilíbrios. Estes são vistos não apenas como um fenômeno normal da vida econômica no capitalismo, 
mas como fatores geradores e/ou propagadores de impulsos microeconômicos originados em última análise a partir de decisões cruciais dosagentesempresariais, dosquaisemergem as propriedades básicas deinstabilidade dinâmica da estrutura econômica capitalista, de um lado, e da mudança estrutural e qual itativa que marca a instabilidadeestrutural intrínseca desta economia, deoutro lado. Estaé uma - talvez a divergência teórico-metodológica fundamental em relação aos modelos do mainstream, mas deforma al guma éaúnica, etem desdobramentos relevantes, como se verá mais adiante.

Em segundo lugar, as correntes fora do mainstream com as quais estamos trabalhando adotam (ou são compatíveis com) as noções de racionalidade limitada e processual proposta por Simon, permitindo conciliar o pressuposto de racionalidade instrumental - do qual a teoria econômica não deveabrir mão, por corresponder a aspectos essenciais da atividade econômica capitalista - com a incerteza em sentido forte (Knight eK eynes), característica de um ambiente que gera inevitavelmentelacunas incontornáveis de informação, de um lado, e a complexi dadeda informação, seja no sentido cognitivo (como interpretá-la), seja no computacional (sua cal culabilidadea custo etempo aceitáveis), deoutro lado. N esse contexto, a racionalidadenão éinviável, mas podeimplicar soluções subótimas (do tipo satificicing, à la Simon), múltiplas edependentes do tempo, levando a possíveis estratégias caracterizadas pela adoção racional de rotinas e convenções. Vejamos mais de perto essas questões.

\subsection{Os pressupostos de racionalidade limitada e processual}

Algum princípio de racionalidade é essencial para microfundamentar qualquer teoria econômica; portanto, é preciso começar por explicitá-lo aqui. A noção básica provém de $M$ ax Weber - a razão instrumental, que supõe simplesmente a adequação de meios a fins. Para ir além disso, é preciso fazer hipóteses mais restritivas. No campo neoclássico, faz parte do paradigma prevalecente assumir adicionalmente (i) maximização de função objetivo (utilidade, lucros) e (ii) consistência das preferências individuais (preferências "fracas" completas e transitivas). Entretanto, a maioria das posições nãoneoclássicas as considera restritivas demais, por serem tidas como (i) inal cançáveis e, em muitos casos, (ii) um fardo "hiper-racional" sobre osagentes. É sobre(i), 
mais geral, que se concentra a argumentação predominante fora do campo neoclássico, em torno principal mente das noções de racional idade limitada (bounded) e processual (procedural) de Simon, por oposição à racionalidade "substantiva" (maximizadora) neoclássica.

É bastanteclaro, mas vale lembrar, quetal "limitação" não é do agente, mas de sua relação com 0 ambiente: ele maximizaria se pudesse. 0 que 0 impede? D uas condições, tipicamente presentes na economia capitalista: (i) incerteza "forte" ou "fundamental" (ou ainda, no essencial, a incerteza "K nightiana") e (ii) complexidade. A presença, mais ou menos generalizada, de(i) torna incompletas as funções objetivo, enquanto a de (ii) torna inviável maximizá-las, por limitações tanto informacionais quanto computacionais. A rigor, as limitações "informacionais" ficam mais claras sob o conceito de racionalidade processual, dentro do qual são vistas como limitações cognitivas. Admitindo, para simplificar a terminologia, que a complexidade está em última análise subordinada à incerteza (seguindo H einer, 1983 esua noção de "C-D gap"), pode-se dizer que a posição do agente racional num ambiente incerto é necessariamente de interação cognitiva com o mesmo. Informações não bastam; épreciso interpretá-las - às vezes, como lembrou Simon (1979), o problema é de excesso e não falta de informações - , o que requer conhecimento sobre como funciona esse ambiente econômico em sua relação com o agente. Assim, a incerteza não se elimina, embora certamente se reduza, pela simples passagem do tempo; de certo modo, é como se o passado também fosse incerto - pelo desconhecimento não de informações, mas das principais relações de causalidade envolvidas.

A importância crucial da incerteza "forte" para a teoria econômica, como Keynes (1936) e Simon (1979, entre outros) já haviam ressaltado, é que ela altera as condições de exercício da racionalidade instrumental por parte dos agentes. Por um lado, se uma decisão econômica deveser tomada, as lacunas da função objetivo devidas à incerteza precisam ser preenchidas com hipóteses e cenários sobreacontecimentosfuturos plausíveis, mas cuja probabilidadenão é calculável objetivamente, podendo dar lugar a previsões sempre passíveis de errossistemáticos. Por outro, a dificuldadedemaximização podeser contornada pela adoção de regras práticas e rotinas, ou ainda pela adoção de soluções subótimas- satisficing, à la Simon. Seguem-seduas conseqüênciasteoricamente 
fundamentais: (i) como os agentes buscam de al guma forma defender-secontra os possíveis prejuízos decorrentes dos (inevitáveis) erros de previsão, adotam comportamentos defensivos em busca de proteção (reservas) e/ou flexibilidade (demanda por liquidez, por exemplo); e como, além disso, (ii) nenhum dos elementosexpectacionaisédeterminável deformaunívoca, o processo de decisão racional sob incerteza gera indeterminação no nível microeconômico; e por extensão em outrosníveis, tornando problemático assumir hipóteses deequilíbrio jáno nível microeconômico mais básico.

É essa ind eterminação básica das expectativas e dos processos de decisão sob incerteza que torna teoricamente possível a priori a adoção de diferentes estratégias por parte de um mesmo agente racional, sob incerteza e, portanto, sob racionalidade limitada. É irrelevante, nesse contexto, que o agente seja "racional" no segundo sentido neoclássico - o de conseguir ordenar completae consistentemente suas preferências e assim definir uma função de utilidade esperada, já que ele não consegue ordenar.

A questão que possivelmente gera mais incompreensão nesse resultado de que incerteza produz indeterminação num processo decisório raci onal - cuja importância para a teoria econômica, vale repetir, dificilmente poderia ser superestimada- équeele parece contrariar um pressuposto usualmenteassociado pelo mainstream da ciência econômica à racionalidade em geral, quando a rigor só está relacionado com a racionalidadesubstantiva neoclássica: 0 de queagentes racionais aprendem a partir da experiência ou da observação. Sob essa premissa, erros de previsão podem acontecer, mas não poderiam ser sistemáticos, como os modelos de expectativas racionais assumem explicitamente. Por ensaio e erro, eadotando critérios Bayesianos de atualização de expectativas, seria questão de tempo a convergência entre as expectativas e a tendência real de um processo econômico.

Com base na argumentação anterior, no entanto, não é possível aceitar essa premissa. Supor que os agentes não cometem erros sistemáticos de previsão porque "aprendem" equivale a suprimir, por hipótese, a presença de incerteza forte, diante da qual, por defini ção, os agentes semprepodem ser surpreendidos por errosnão insignificantes, dadaa naturezanão-cal culável do desconhecimento do futuro (e não só deste) envolvido. N esse quadro, faz mais sentido assumir queos agentes racionais, após a devida experimentação, finalmenteaprendem - 
que não aprendem! 0 aprendizado na economia capitalista se resume àquelas circunstâncias, quenão são muitas, em queocorrem regularidades importantes (e.g. trajetóriastecnológicas).

$\mathrm{N}$ ão édiferentea posição - a meu ver, essencialmente correta- deD avidson em seu artigo pioneiro (1982/3) e, posteriormente, deVercelli (1991, cap. 5), quando chamam a atenção para as premissas diametralmente opostas assumidas por K eynes, de um lado, e pelo modelo de expectativas racionais, de outro: 0 pressuposto de incerteza "forte", ao contrário desteúltimo, implicaum ambiente econômico (capitalista) no qual os processos relevantes são não-ergódicosenãoestacionários, tornando irrelevante(ou, como propôsD avidson, "irracional"...) uma "atualização", bayesiana ou semelhante, de expectativas construídas em base probabilística. Ressalte-se de passagem uma essencial conseqüência lógica dessa conclusão: ela não invalida apenas - como reconheceu o próprio Lucas (1981) para o caso de processos não-estacionários - a adoção de expectativas racionais num mundo econômico quenão se suponha estacionário (e, maisque isso, ergódico): a presença de incerteza "forte", relacionada biunivocamente a ambientes não-ergódicos e não-estacionários, invalida também a aplicação de qualquer noção de raci onalidade substantiva ou maximizadora de uma função objetivo determinável (ainda quenão determinística) como microfundamento da teoria econômica, impondo em seu lugar alguma noção de racionalidade limitada. 0 alcance da crítica é, portanto, maior do que poderia parecer.

É importante observar também que a incorporação de probabilidades subjetivas, na tradição de Savage ou semelhante, não resolve o problema, como pretende Lisboa (1997). A insistência de Keynes em que incerteza exclui probabilidades "objetivas" não é obsoleta (não decorre, por exemplo, de que Savage e D eFinetti sejam obviamente muito posteriores, ou ainda que tivesse um ponto de vista "objetivista" em probabilidades, contra o "subjetivista" desses autores); ao contrário, porque é um argumento logicamente geral. Keynes também considerava que os agentes formam probabilidades subjetivas, até porque não as considerava atributos "do mundo real", mas das proposições sobre ele. 0 problema da "falta de objetividade" das decisões dos agentes econômicos no mundo real - que Keynes assumia como sujeito a incerteza, e portanto não-ergódico e não-estacionário - , é que estes não têm elementos objetivos, não só para formular, mas também para atualizar (ou aprender, de 
forma Bayesiana ou outra) tais probabilidades, assim como as expectativas decorrentes. D aí que as decisões mais afetadas por incerteza "forte" - como as deinvestir - sejam indeterminadas, o que obviamentenão quer dizer "irracionais".

Probabilidades construídas com base objetiva (ainda que "subjetivas" no sentido de Keynes) podem ser de duas ordens: baseadas ou no conhecimento (teórico) das "leis de formação" do respectivo fenômeno, ou na freqüência (empírica) observada do mesmo. Processos insuficientemente conhecidos teoricamente (cientificamente) ecom poucos elementos (seal gum) prévios de observação - por serem, repito a premissa, não-ergódicos enão-estacionáriosnão podem ser projetadosestatisticamente com margem deerro pré-determinada. Foi o que levou Keynes a sugerir que as expectativas econômicas mais impregnadas de incerteza devam ser descritas por dois atributos, e não apenas um: a probabilidade (subjetiva) e o grau de crença (ou confiança, ou ainda o "peso do argumento") depositada pelo agentena previsão feita. Esses atributos não são redundantes: para Keynes, pode-se atribuir uma probabilidadealta a um resultado por meio de um cálculo cuja base informacional ou cognitiva tem confiabilidadebaixa, evice-versa. Em suma, reduzir (equantificar) osproblemas acarretados pela presença deincerteza apenasa probabilidadessubjetivaséomitir queo atributo do grau de confiabilidadeé no mínimo tão importantequanto 0 valor atribuído à probabilidade, equeisso podepor si só mudar qualitativamente o processo de decisão.

Finalmente, cabeainda assinal ar o resultado potencialmente drástico de que o ambiente econômico de incerteza "forte" é um ambiente que apresenta instabilidade estrutural (Vercelli, 1991, cap. 4), isto é, variabilidade dos parâmetros segundo traj etórias que não são determináveis a priori, nem mesmo estocasticamente. N ão há como supor "fundamentos econômicos" estáveis (preferências, tecnologia, etc.), que possam definir equilíbrios tendenciais, seja como em model os de expectativas racionais ou como em modelos (inclusive não-neoclássicos) queassumem algum "equilíbrio delongo prazo". A presença deprocessos endógenos demudança estrutural, especial masnão exclusivamente relacionados a inovações schumpeterianas promovidas em busca de lucros extraordinários (fora do equilíbrio), éuma condição, além de universalmente presente na economia capitalista, inteiramente suficiente para produzir tal resultado, que, por sua vez, assegura a permanência, em graus variados, mas 
sistemática, de processos não-ergódicos e não-estacionários e, com eles, de incerteza "forte".

Em síntese, argumentou-se que, sob incerteza "forte", a identificação tradicional deracionalidadecom maximização defunção-objetivo bem definida (o que pode incluir elementos estocásticos) precisa ser abandonada por uma noção de racionalidadelimitada, ou ainda, processual. E queisso leva a múltiplas soluções para os problemas de decisão racional, seja porque as funções-objetivo - lucro esperado, por exemplo - possuem lacunas que podem ser preenchidas com diferentes "cenários" sob diferentes graus de confiança, seja porque, em lugar detentar maximizá-lassistematicamente, freqüentemente os agentes optem por soluções subótimas ou mesmo "regras práticas", rotinas ou al go semelhante, o que não exclui métodos "inovadores" de obter soluções (ver a respeito D osi e Egidi, 1991). Assim, e apesar da aparência "caótica" que a presença de indeterminação teórica poderia sugerir, regularidades comportamentais são um resultado provável da presença de incerteza "forte" e dos comportamentos defensivos que ela enseja. A instabilidadeestrutural, paradoxalmente, induz um grau considerável deestabilidade comportamental. N ostermos deH einer (1983), os comportamentos tendem a ser mais estáveis que o sistema ambiente, e serão tão mais estáveis quanto maior o grau deincerteza. Sea presença de regularidades éum requisito para construir teorias científicas, éimportanteconstatar queele étambém satisfeito sob incerteza "forte".

É claro quea construção de modelos sob tais premissas émais difícil esó conduz a soluções analíticas sob hipóteses muito restritivas; em geral exigindo análise por simulação e/ou um esforço teórico qualitativo e preliminar de construir tipologias de estratégias empresariais e/ ou de características setoriais da tecnologia e da concorrência. D o ponto de vista formal, o pressuposto de que sob incerteza e complexidade surgem decisões racionais de tipo estratégico, no sentido usual (decisões interdependentes no tempo), equivalea admitir que 0 ambiente econômico no qual elas são formadas é não-ergódico e nãoestacionário; o que implica um deslocamento substancial do eixo teóricometodológico em relação à tradição do mainstream.

As correntes citadas apresentam contribuições relevantes a este tema, embora ainda não sistemáticas. D o campo pós-keynesiano é evidentea sintonia com a noção de incerteza, "forte" (Knight-K eynes) e não-ergodicidade do 
ambiente econômico, dando lugar a estratégias defensivas e comportamentos convencionais. Por outro lado, élugar - comum queincerteza e complexidade "geram" instituições (ainda que estas existam previamente), o que aponta não só para grande parte da herança teórica de Keynes, como também para as correntes neo-institucionalistas. À diferença do antigo institucionalismo, tais correntes não mais assumem um viés antiteórico; ao contrário, caracterizam-se entre outros aspectos por considerar que as atividades e decisões econômicas estão imersas num ambiente socio-institucional que condiciona e até codetermina, por diferentestipos de feedback, as decisões econômicas, deforma que uma teoria econômica rel evante deve incorporá-lo em seus fundamentos. D e outro lado, por parte dos neo-schumpeterianos é notória a filiação, "behaviorista" - aos trabal hos de H. Simon - dos fundadores da corrente evolucionária, R. N elson e S. W inter, que, ao lado de muitos outros têm trabal hado a idéia de diferentes, padrões de racional idadeestratégica envolvendo comportamentos rotineiros e inovativos num ambiente incerto e complexo.

\section{Os aportes de Keynes e dos pós-keynesianos}

\subsection{Formação de expectativas sob incerteza}

$\mathrm{N}$ ão obstante o interesse e a dificuldade em formular, e eventual mente formalizar, os problemas de operar com probabilidades subjetivas e a partir delas tomar decisões sob incerteza, a meu ver o problema possivelmentemais desafiador dessa agenda de pesquisa teórica éo da formação das expectativas sob incerteza, que ganhou particular destaque no programa de pesquisa da corrente pós-keynesiana. Em outras palavras, trata-se de buscar o quanto possível sistematizar o conteúdo das previsões (e das respectivas probabilidades subjetivas, quando for o caso) que, sob incerteza, os agentes constroem e introduzem em suas expectativas - por exemplo, de curto e longo prazos, seguindo K eynes. Este é um primeiro aspecto a ser observado: a distinção entre expectativas de longo e de curto prazos, estando as primeiras - relativas aos investimentos - sujeitas a um grau de incerteza substancialmente maior. A principal conseqüência disso étorná-las, em princípio, muito mais exógenas (ainda que não inteiramente) que as de curto prazo. 
A principal dificuldadeéque, a qual quer prazo ecircunstância, a presença sistemática, ainda que variável, de incerteza retira a possibilidade de efetuar previsões a partir der eferências quesejam claramentemais seguras ou confiáveis. $N$ ão parece haver regra geral: excluída, por hipótese (de que os processos relevantes não são estacionários nem ergódicos), a formação de expectativas racionais, diferentes combinações de expectativas adaptativas (endógenas) com componentes exógenos ("cenários", por exemplo) são plausíveis.

U ma das pistas teóricas mais promissoras, ainda que nem de longe suficiente, équea formação de expectativas sob incerteza pode também aderir a procedimentos recursivos de tipo rotinas - que ademais representa uma fonte adicional (potencial) de regularidades. Em outras palavras, a presença de incerteza (e complexidade) pode induzir não só a rotinas comportamentais em substituição a procedimentos maximizadores, como visto, mas também a rotinas expectacionais, em complemento ou substituição a funções-objetivo incompletas por lacunas de informação e cognitivas. Um forte candidato a esse papel é a noção de convenção proposta por Keynes (Teoria G eral, cap. 12), que, embora formulada no âmbito de expectativas de mercados financeiros, pode ser estendida a outros mercados em geral, até porque se refere às expectativas de longo prazo, que por hipótese são as mais sujeitas, pelo tempo mais extenso e menor liquidez envolvidos, a um alto grau de incerteza. E uma das "convenções" mais simples e por isso prováveis (porque de fácil adesão) é a projeção do passado recente para o futuro imediato, na fal ta de hipóteses confiáveis de que al go vá mudar; na expressão deK eynes, a "teoria prática do futuro".

A adesão a esse tipo de convenção permite a cada agente acompanhar a maioria, e com ela a tendência mais provável, com isso minimizando riscos. E mesmo que não haja adesão - porque o agente prefere enfrentar os riscos - , ainda assim a "convenção", caso exista, éuma referência crucial para o mercado. Trata-se, numa primeira aproximação, de uma justificativa teórica mais consistente para a adoção de expectativas adaptativas, freqüentemente descartadas pela ortodoxia (principalmente novo-clássica) como irracionais ou ad hoc. Em princípio mais adequadas às decisões de curto prazo (produção epreços), nada impede estendêlas para o longo prazo (investimento), embora nesse caso só parcial mentee com qualificações. 
Certamente outros tipos de formação "rotineira" de expectativas podem ser pensados, mas éinteressantetentar explorar o potencial teórico dessa noção keynesiana, especialmente quando aplicada às deci sões de investimento, devido não só ao maior desafio teórico envolvido, mas particularmenteà sua importância crucial para a dinâmica econômica. 0 grande impacto potencial desse tipo de formação "convencional" de expectativas deve-se ao fato de que supõea adesão degrandenúmero deagentes, dando lugar a expectativas compartilhadas (ainda quenão necessariamenteconsensuais; ésuficienteuma distribuição concentrada em torno da média), que por isso mesmo tendem freqüentementea seconfirmar pelo fato de existirem - as chamadas "profecias auto-realizadas", de óbvia importância macroeconômica.

Assim, a geração de regularidades comportamentais de natureza expectacional, quese reproduzem não só no tempo, mas também "no espaço", Ionge de implicar estabilidade, implicam freqüentemente maior instabilidade (dinâmica). Isso éparticularmenteverdadeiro quando essespadrões expectacionais são aplicados à análise dos investimentos e seus efeitos macroeconômicos, seja na forma deciclos - de desequilíbrio, como os de K al ecki ou neo-keynesianos tradicionais, não os de equilíbrio novo-clássicos- , ou simplesmentena forma desurtos especulativos de crescimento ou de valorização/desval orização deativos. V ista por esseângulo - queéo mesmo do cap. 12 da Teoria Geral deKeynes - , a especulação não é uma disfunção, nem mesmo é muito diferente do "empreendimento normal".

M as a formação "convencional", ou de algum outro tipo "rotineiro", das expectativas, apesar daimportância queacredito ter, estálongedeesgotar o assunto. Sob incerteza, as expectativas, especialmente delongo prazo (investimentos), na falta dereferências compartilhadas, são em grandemedida exógenas, o que, senão inviabiliza, certamentetorna mais difícil a formação deconvenções, ao menosem horizonte de tempo não muito extenso. Como observado antes, essa indeterminação do conteúdo das expectativas abre espaço para a construção de múltiplas estratégi as por parte de cada agente, num contexto de racionalidade limitada, no qual a escolha unívoca de uma dada estratégia como "a mais racional" éfreqüentementeimpossível, por envolver incerteza "forte".

Para tratar teórica e analiticamente comportamentos estratégicos, elementos de teoria dos jogos devem ser usados com cautela, porque: (i) seus 
pressupostos metodológicos são quase sempre de racionalidade substantiva (maximização de payoffs), e(ii) em decorrência, a noção de estratégia só contém incerteza conjectural (em relação a reações dos rivais, quando sob informação incompleta), enão incerteza "forte", queénecessariamente sisêmica (envolvendo não só os denominados "estados denatureza" como também ospróprioscenários estratégicos e os payoffs esperados pelos agentes em interação). Em suma, a noção de etratégia aqui empregada - mais próxima do senso comum do mercado e das empresas - supõe uma seqüência temporal mente consistente e determinada de decisões, construída sob racionalidade limitada, com regras previstas de saída à la H einer (1983) - significando que nem todo desvio da previsão leva a mudar a estratégia.

Creio que o principal item na agenda teórica de pesquisa sobre o tema das expectativas sob incerteza seja exatamente o de procurar sistematizar comportamentos estratégicos, por exemplo na forma detipologias deestratégias, quepossam incorporar, indo no entanto muito além deste, o comportamento "convencional". O s efeitos dinâmicos, inclusivemacroeconômicos, teoricamente esperados das diferentes hipóteses acercadepadrões estratégicosdediferentes agentes (empresas) em diferentesmercados, poderiam assim ser extraídos pari passu. Em conclusão, a agenda da teoria macrodinâmica sob incerteza e seus avançostem necessariamente de estar atrelada à agenda e aos avanços, infelizmente ainda muito incipientes, da teoria da formação de expectativas - particularmente as delongo prazo - sob incerteza.

\subsection{Desequilíbrio e dinâmica econômica: da instabilidade de Keynes à dinâmica dos modelos neo-keynesianos e de Kalecki}

A suposição de que desequilíbri os e fal has de coordenação pertencem ao cotidiano da economia demercado - intrinsecamente uma economiamonetária - écomum às distintas correntes heterodoxas, notadamenteà pós-keynesiana, à institucionalista eàneo-schumpeteriana. Ela equivalea supor que, nesteambiente não-ergódico enão-estacionário que caracteriza a economia capitalista, os agentes podem cometer erros de previsão sistematicamente, sem por isso serem irracionais, e os mercados podem não estar em equilíbrio (e portanto "cleared", embora a recíproca possa não ser verdadeira) mesmo em condições competitivas. 
Assim, tanto num contexto estático (tratado como equilíbrio geral competitivo) quanto na dinâmica de uma trajetória temporal, a imposição de condições de equilíbrio como um prérequisito da análise científica, amplamente defendida pela macroeconomia novo-clássica e empregada pela N ED, torna-se uma restriçãa, além de desnecessária, sufocante. Grande parte da tradição teórica do crescimento e do ciclo econômico até os anos 1960 (não neoclássica: neo-keynesiana ou schumpeteriana) assumia a ocorrência de desequilíbrios como parte integrante da dinâmica econômica, seja por sua própria natureza e seus efeitos, seja em sua propagação em torno de uma tendência de equilíbrio móvel ou ainda de uma tendência que não constitui equilíbrio necessariamente.

Ambas as dimensões, monetária e institucional, dos problemas de coordenação dos mercados, embora eventualmente focalizados por autores do mainstream, têm um papel certamentemuito maiscentral tanto naantiga agenda neo-keynesiana quanto naatual pós-keynesiana. N esse sentido, o desequilíbrio e mesmo a instabilidade potencial ${ }^{2}$ do sistema de mercado são, para essas correntes, uma referência intelectual tão central quanto é o seu oposto, 0 equilíbrio geral competitivo (em geral suposto único e estável, mesmo quando não explicitado), para o mainstream.

$\mathrm{Na}$ perspectiva da construção de um esquema integrado de análise, eventualmente um modelo dinâmico, que incorpore elementos keynesianose pós-keynesianos, cabereferir, em primeirolugar edemodo especial, ao princípio dademanda efetiva . Sua principal implicação émetodol ógica, ao demonstrar, contra um certo senso comum difuso e implícito do mainstream neoclássico e a partir dele para a esmagadora maioria dos economistas, queépossível definir relações de causalidade unilateral bem determinada em Economia - no caso, entre gasto (determinante) e renda (determinada) - sem referência a qual quer noção de equilíbrio.

Em segundo lugar, vale destacar algumas implicações dinâmicas fundamentais do próprio princípio da demanda efetiva no sentido de gerar efétos de indução sobre as decisões de produção e deinvestimento das empresas, muito importantes na tradição neo-keynesiana de modelos de crescimento e

Dinâmica e estrutural - ver Vercelli (1991), caps. 2 e 3.

3 Ver uma discussão detalhada recente em Possas (1999b). 
ciclo econômico com base na interação multiplicador-acelerador, ${ }^{4}$ mas hoje praticamenteabandonados. A perspectiva aqui éa de explorá-los intensamente, embora num enfoque al ternativo - certamente, não em mera reprodução dos modelosneo-keynesianos - de dinâmica macroeconômica. ${ }^{5}$

É claro que não se trata de um simples retorno aos modelos da família $\mathrm{H}$ arrod-D omar, até porque esses modelos são agregados- o que éincompatível com o enfoque multissetorial aqui proposto - e teoricamente pobres, mesmo num contexto keynesiano deanálise. Por exemplo, registre-senessesa ausência de uma teoria minimamente satisfatória do investimento, que é explicado pelo mecanismo simplista do acelerador. 0 desejável épreencher essa lacuna em grande medida com elementos extraídosna teoria deaplicação decapital presenteno cap. 17 da Teoria Geral de Keynes, apud M insky (1975), adicionada de elementos analíticospropostosem K alecki (1954, cap. 9). Além disso, será essencial suprir a ausência de progresso técnico endógeno típica desses modelos com a análise schumpeteriana eem particular com aneo-schumpeteriana, como járessaltado.

Em terceiro lugar, cabetambém lembrar o conceito deinstabilidadepresente em Keynes, que pode ser caracterizado, antes de um conceito propriamente dinâmico, como uma noção de instabilidade potencial. ${ }^{6}$ Ainda que um esquema de análise mais específico, e em particular um modelo, não possa contentar-se com uma noção de efeito "potencial" como esse, éimportante pelo menos têlo semprepresente, no sentido metodológico essencial de que qualquer esquema de anál ise ou modelo quepretenda retratar com um mínimo defidelidadea dinâmica de uma economia capitalista não podeignorar que a formação de expectativas de longo prazo devenecessariamenteestar sujeita mecanismosendógenoscumulativos ("feedback" positivo) do ponto de vista macroeconômico - isto é, por "contaminação" coletiva presente no processo mesmo de formação dessas expectativas, que setornam com isso capazes de desencadear crises.

\footnotetext{
É interessante notar como todos esses modelos tinham total ênfase na demanda, já que tanto o multiplicador quanto o acelerador são efeitos centrados no ajuste da oferta - via produção, emprego e renda, no primeiro caso, e via capacidade produtiva, no segundo - à demanda agregada, determinada pelas decisões de gasto endógenas sumo e investimento - dos agentes.

5 E não apenas num contexto de "curto prazo", como às vezes se supõe erroneamente. Basta considerar a importância, para a tendência de expansão a longo prazo, dos componentes autônomos do gasto agregado, em particular (mas não exclusivamente) o investimento não induzido por mudanças na atividade corrente, mas de longa maturação (inclusive público) ou associado a inovações ou "fatores de desenvolvimento", como tratado por Kalecki (1954, cap. 15) e vários outros, incluindo o próprio artigo original de Harrod (1939).

6 Ver a respeito Possas (1986), p. 305 ss.
} 


\section{Os aportes do enfoque evolucionário neo-schumpeteriano}

No que se refere à corrente neo-schumpeteriana, apesar de um certo desinteresse pelas questões monetárias e institucionais rel ativas à coordenação dos mercados, éinegável a pertinência destas para sua preocupação crucial com a dinâmica econômica no seu sentido maisforte - o da mudança institucional centrada no progresso técnico - , que dálugar à presença deinstabilidadeestrutural (no sentido acima) das trajetórias possíveis da economia capitalista. 0 desequilíbrio, portanto, mais até do que uma possibilidadereal que podegerar crises, como nos pós-keynesianos, épara essa corrente uma característica essencial edominante da economia capitalista.

Em conseqüência, as trajetórias de longo prazo de indústrias ou do conjunto das economias capitalistas podem (e devem) ser analisadas, coerentemente com o quadro anterior, fora do equilíbrio. Podem apresentar, além disso, importantes não-linearidades, decorrentes de aspectos cumulativos de decisões empresariais e de seus efeitos estruturais (aprendizado, sinergias, etc.); e regularidades, capazes de reduzir a incerteza (sem eliminá-la) e balizar as decisões de longo prazo dos agentes, atenuando os efeitos de instabilidade potencial do outro fator. 0 progresso técnico e correspondentes trajetórias tecnológicas ${ }^{7}$ é claramente um dos principais processos dinâmicos capazes de gerar tais efeitos delongo prazo, ao criar ao longo do tempo dependência crescente de ativos adquiridos inicialmente, que geram efeitos de path dependence com rendimentoscrescentesecustosirrecuperáveis(sunk costs) crescentes, eventualmente proibitivos. ${ }^{8}$ A presença deinstituições estáveis podegerar efeitosanálogos, ainda que mais complexos e certamente menos estudados pel os economistas.

Já existe uma considerável literatura neo-schumpeteriana abordando diferentes aspectos teóricos das trajetórias de longo prazo, suas fontes de instabilidade/ estabilidade e de regularidade, especificamente relacionadas ao processo inovativo nas empresas/indústrias e às correspondentes trajetórias tecnológicas. N umerosos modelos dinâmicos têm sido desenvolvidos, caracterizados como evolucionistas ou evolucionários, isto é, cuja trajetória temporal resulta de processos microeconômicos de geração endógena de

Ver a respeito Dosi (1982) e (1984).

8 Podendo gerar efeitos de "lock in": ver Arthur (1994). 
diversidade, com base em estratégias competitivas inovativas das empresas selecionadas pelo ambiente (mercado).

0 desenrolar desse processo interativo no tempo se caracteriza por mudanças freqüentes nos parâmetros tecnológi cos e expectacionais dos agentes (não-linearidades), sem produzir - em princípio e em geral - convergência a equilíbrio nas trajetórias, indeterminadas a priori, em cuja direção incidem tanto efeitos cumulativos de path dependence, capazes de provocar instabilidade, quanto efeitos de flutuação ou de convergência (ou ainda de "auto-organização"), que tendem a estabilizá-los. 0 resultado é quase sempre imprevisível, pela complexidade dos fatores envolvidos, podendo-se obter as trajetórias resultantes por simulação, a partir de hipóteses ad hoc sobre condições iniciais e modificações nos parâmetros, em lugar de soluções matemáticas e analíticas bem definidas e general izáveis.

D a extensa literatura pertinente cabecitar, em primeiro lugar, o modelo pioneiro de $\mathrm{N}$ elson e W inter (1982), que deu início a uma série de modelos que tratam a dinâmica industrial (setorial) como um processo evolucionário baseado na concorrência schumpeteriana. Essa dinâmica resulta de mudanças técnicas e econômicas decorrentes do esforço inovativo de cada firma, obedecendo a uma estratégia inovativa ou imitativa expressa em investimentos de $P \& D$. A competitividade e a lucratividade de cada firma em cada período decorre do sucesso inovativo/imitativo anterior e dos investimentos em nova capacidade. 0 investimento em $P \& D$ influi na probabilidade de sucesso basicamente por meio de um processo estocástico de M arkov. A mudança de estado da firma é dada recursivamente ao longo de uma simulação, de modo a gerar uma trajetória dinâmica.

$\mathrm{N}$ uma segunda leva de modelos, vale observar que ocorre como que uma "bifurcação" detipos de modelos evolucionários neo-schumpeterianos: de um lado, como mostra o survey deSilverberg (1988), merecedestaque o modelo de Silverberg, D osi e O rsenigo (1988), para uma trajetória com mudança tecnológica; deoutrolado, emais recentemente, servede exemplo o modelo de Silverberg eVerspagen (1994).

0 primeiro modelo foi elaborado com base em um modelo anterior de Silverberg (1987), voltado basicamente para a difusão, e não a geração, de progresso técnico. No âmbito da produção e da demanda, o modelo utiliza 
uma equação de tipo biológico ("replicator dynamics"), que faz o market share de cada firma depender da diferença entre sua competitividade e a competitividade média das firmas da indústria. No âmbito da mudança tecnológica, introduz um modelo de safras com incorporação progressiva de progresso técnico nos equipamentos de reposição; a substituição dos antigos obedece a uma regra de período de payback. 0 investimento produz assim efeito tanto sobre o estoque de capital quanto sobre a eficiência técnica (que ainda inclui aprendizado).

U ma interessante tentativa de integração entre o modelo pioneiro de $N$ elson eW inter e o deSilverberg et al éa deC hiaromontee D osi (1991), que trata a economia como um todo como representada por dois setores verticalmente relacionados: um de bens de capital (tratado ao estilo $\mathrm{N}$ elson e W inter) e outro que os utiliza (tratado ao estilo deSilverberg et al). Entretanto, embora a modelagem proponha refinamentos interessantes no mecanismo de busca deinovações, a integração éapenas parcial e não muito satisfatória.

Recentemente, nossa equipe de pesquisa realizou um esforço adicional no sentido da mesma integração entreaqueles modelos, ${ }^{9}$ mas com a incorporação deelementos comportamentais não-neoclássicos (com racionalidadelimitada) mais explícitos, tais como formação de expectativas adaptativas tanto de curto como de longo prazo; ausência de equilíbrio de market clearing no funcionamento do mercado; formação de preços por mark up desejado combinado com o preço médio da indústria (apud Kalecki) ${ }^{10}$, com mecanismo de feedback a partir do mark up efetivo al cançado; e restrição financeira, via endividamento, às decisões de investir (apud Keynes eK al ecki).

0 segundo tipo de modelo, mais focalizado sobre o crescimento macroeconômico de uma dada economia, assume múltiplos agentes e aprendizado coletivo, supondo uma economia sujeita a crescimento endógeno. No nível microeconômico, Silverberg e Verspagen (1994) assumem que as firmas decidem os investimentos em $P \& D$ na expectativa de conseguir sucesso inovativo, o qual éuma função estocástica desse esforço de $P \& D$. As vantagens econômicas resultantes da inovação são temporárias, à medida que estas se difundem tanto dentro da firma como entre firmas.

\footnotetext{
9 Veja-se Possas, Koblitz, et al. (2001).

${ }^{10}$ Kalecki (1954), cap. 1.
} 
Um problema metodológico sério desse segundo tipo de modelo, que o torna inadequado à proposta aqui assumida, éa ausência de uma estrutura econômica definida com padrões de especialização setorial e de interrelação setorial (consumo, investimento, insumos), essencial em qualquer análise macroeconômica. Em outras palavras, a passagem micro-macro é feita sem mediações entre as empresas e o conjunto da economia, tanto via relações insumo-produto como via geração de renda e demanda final, o que equivale a dizer que, do ponto de vista analítico, o model o não possui nenhum nível macroeconômico. Essa lacuna o torna inaplicável para a integração micromacroeconômica pretendida. Assim, a proposta discutida a seguir se apoiará no primei ro tipo de model o setorial, como aquele por nós desenvolvido, para servir debase setorial ou "microfundamentada" à elaboração da passagem micromacro - necessariamente multissetorial - requerida para a análise da dinâmica macroeconômica.

\section{Proposta de integração micro-macrodinâmica: linhas gerais}

U m esforço adicional de aprofundamento de análise na direção antes sugerida, com ênfase na elaboração de model os multissetoriais de simulação, justifica-se pelo menos pelos motivos básicos que seguem.

0 primeiro emais geral équea proposta teórica antes esboçadaéclaramente uma ambiciosa linha depesquisa, que por sua amplitudee complexidade envolve grande número de participantes em âmbito internacional e deverá tomar um tempo considerável dematuração; nosso aportecertamenteéapenas uma pequena partedesse esforço. Especificamente, as direçõesmaispromi ssorasdenossa possível contribuição a esse esforço consistem em suplementar a literatura teórica e modelística evolucionária/neo-schumpeteriana com:

(i) a inclusão de elementos considerados como macroeconômi cos, mas que são totalmente incorporáveis num arcabouço multissetorial e dinâmico, seja de extração keynesiana (em particular os monetários efinanceiros, relativos às decisões deinvestir) ou kaleckiana (especialmenteos relacionadosà formação de preços, à demanda efetiva e aos efeitos dinâmicos do investimento), que possibilitarão uma articulação micro-macro, quase inteiramente ausente dos model os neo-schumpeterianos; 
(ii) aspectos relativos ao desenvolvimento econômico, que apesar de a teoria dinâmica de Schumpeter ter sido explicitamente uma "teoria (geral) do desenvolvimento capitalista" permanecem ainda distantes das preocupações dessa literatura, quetem preferido limitar-se, na vertente "microdinâmica" (a quenos interessa mais deperto), à análiseemodelagem detrajetórias dinâmicas desetores industriais sob progresso técnico. Como jámencionado, nassuas poucasincursões nessa direção, ela tem oscilado entre uma simples (embora inteligente) reconstituição de "fatos estilizados" ou defatoresinstitucionais rel evantes para o desenvolvimento (cf. número especial de Industrial and CorporateC hange, 1-1994) e modelos de longo prazo agregados e estilizados em nível de países, mas com microfundamentação precária pelafalta dearticulação entrea evolução setorial, vista como centrada na mudança técnica, e o comportamento macroeconômico (como nos modelos de Silverberg e Verspagen); e

(iii) a incorporação, em forma analiticamente clara, de elementos institucionais, reconhecidamenteessenciais para uma teoria do desenvolvimento. À diferença dos enfoques de tipo explicitamente histórico/institucional, complementares ao nosso mas demenor densidade teórica, nosso objetivo nesse aspecto é incorporá-los em medida adequada e sob hipóteses "estilizadas" razoáveis, num esquema analítico e modelístico predominantemente teórico, em lugar de histórico-descritivo como tem sido a tônica dessa literatura.

O segundo motivo básico que desafia ejustifica o esforço aqui proposto é a ênfase metodológica em modelos desimulação, em contrasteaos modelos de equilíbrio convencionais. I sso implica detalhar os aspectos quantitativos da análise, sem perder de vista os qualitativos- escolhendo pressupostos ehipóteses comportamentais, transformando estas últimas em equações e procurando parametrizá-las de forma compatível com "fatos estilizados" conhecidos. Tal ênfase na construção de modelos de simulação, ou de resultados mais determinados, não implica abrir mão do reconhecimento do caráter intrinsecamentehistórico e institucional de qualquer dinâmica econômica no capitalismo, e a fortiori do processo de desenvolvimento; mas impõe a preocupação de avançar analiticamente para além das considerações genéricas cultivadas pela tradição anterior da Economia do D esenvolvimento, nas suas vertentes menos ortodoxas (emaisinteressantes), eque pareceter sido em parte responsável pelo seu progressivo isolamento acadêmico eintelectual. 
A estrutura básica do modelo dinâmico de simulação multissetorial (micro-macrodinâmico) que estamos desenvolvendo na perspectiva indicada acima está apoiada num modelo dinâmico multissetorial el aborado nos anos 1980, ${ }^{11}$ eque se caracteriza pelos seguintes aspectos fundamentais:

(i) 0 núcleo dessemodelo multissetorial consistena utilização de matrizes de relações intersetoriais, tanto a matriz quadrada de insumo - produto convencional (construída na forma setor $x$ setor, supondo um mix homogêneo de produtos por setor), quanto matrizes destinadas à endogeneização de componentes da demanda final, a saber: matriz (setor $x$ setor) debens de capital; matriz (classe de renda funcional $x$ setor) de apropriação funcional de rendimentos; matriz (classe de renda pessoal $x$ classe de renda funcional) de apropriação pessoal de rendimentos; matriz (classe derenda pessoal $x$ classe de renda pessoal) de apropriação de rendimentos por serviços pessoais; e matriz (classederenda pessoal $x$ setor) de consumo. Essa estrutura intersetorial permite endogeneizar os principais componentes da demanda final (investimento e consumo), exceto setor externo egoverno, que devem receber tratamento em separado eem grande parte exógeno.

(ii) Apesar do lugar-comum de que matrizes de insumo-produto são intrinsecamenteestáticas, pelo fato de os coeficientes das matrizes serem fixose por isso não se prestarem a um tratamento dinâmico, foi justamente esse 0 objetivo precípuo da construção do modelo. Essa percepção éequivocada, tendo sido desmentida por váriastentativas anteriores, desdePasinetti, no plano teórico, atéo próprio Leontief, no plano aplicado. Para nossos propósitos, que envolvem relações de determinação baseadas na demanda efetiva esem qualquer referência a posições de equilíbrio ou a mecanismos de ajustamento, essa questão simplesmente não se coloca: os coeficientes só são dados (não "fixos" ou constantes) durantecada período de simulação, podendo mudar segundo regras pré-determinadas, exógenas ou não, entre períodos. Como estes são, por hipótese, intervalos entre as decisões consecutivas dos agentes (produção, investimento, consumo), logicamente não surge nenhum problema pelo fato deserem dados durantecada período esó poderem ser revistos ao fim do mesmo; isso corresponde exatamente ao que ocorre na realidade. $M$ as, vale repetir, o

11 Possas (1983), publicado em versão mais compacta em Possas (1984). 
resultado que se espera obter são trajetórias dinâmicas com tempo discreto (períodos) sem equilíbriosa priori, diferentementeda grandemaioria dosmodelos multissetoriais que utilizam o instrumental de matrizes de Leontief.

(iii) D e forma coerente com a ausência de pressupostos de equilíbrio, o modelo assumehipóteses keynes-kal eckianas associadas à demanda efetiva, assim resumidas: a demanda dirigida a cada setor determina suas vendas (expressas em quantidades ou em termos reais), ${ }^{12}$ restringidas por estoques; a produção é programada a partir de expectativas adaptativas (de tipo extrapolativo) com base nos períodos de produção mais recentes, e restringida pala capacidade instalada; e esta é decidida com base em expectativas extrapolativas de períodos de investimento anteriores, sendo o valor do investimento restringido pela capacidade financeira deendividamento das empresas. 0 s preços, por sua vez que não afetam em princípio o nível de vendas - são dados por mark up sobre os custos variáveis unitários, o que determina estruturas setoriais de distribuição funcional derenda, indispensáveis para endogeneizar o consumo no modelo.

$\mathrm{N}$ a versão atualmente em elaboração, essa estrutura básica é mantida, sendo as principais modificações ou acréscimos como segue:

(i) A estrutura matricial do modelo permanece, exceto pela circunstância de o software utilizado permitir simplificar a simulação de mudanças não só exógenas, mas endógenas, dos parâmetrose coeficientes setoriais a cada período. I sso facilita endogeneizar intei ramente os coeficientes microeconômicos, desde a produtividade (em função daintensidade do progresso técnico de cada empresa em cada setor) até os mark ups e preços praticados individualmente. A oferta (produção + estoques) e a demanda, em termos reais, de cada setor são endogeneizadas aplicando-se para cada setor a estrutura do modelo setorial desenvolvido em Possas, Koblitz (2001). A demanda setorial, afetada pelo preço médio do setor via elasticidade-preço, édistribuída entreas respectivas empresas pelo critério de competitividade individual, dada pela equação de replicator, usada naquele modelo para determinar os market shares em função da competitividade decada empresa.

(ii) 0 consumo por classederenda pessoal édefinido por funções-consumo linearescom defasagens crescentes epropensõesmarginaisa consumir decrescentes

\footnotetext{
${ }^{12}$ Supõe-se em geral preços rígidos no período de mercado ("fixprice"). Situações específicas de preços flexíveis ("flexprice") podem ser convertidas ao caso anterior supondo-se valores razoáveis de elasticidade-preço da demanda.
} 
com o nível derenda, bem como componentesautônomos elevadosevariáveispor simulação. A distribuição setorial funcional derenda éfunção dosmark upsmédios e dos salários médios, que podem ser objeto de simulação em separado. Os investimentos são determinados ao nível de cada empresa, abrangendo tanto a ampliação decapacidade como a modernização eintrodução de progresso técnico incorporado. 0 sucesso dos esforços de P\& D é uma variável estocástica, assim como o deslocamento dafronteira deprodutividade, seguindo o modelo deN elson \& W inter, conformeadaptado em Possas, Koblitz (2001).

(iii) Além dessenúcleo endógeno do modelo multissetorial, trêsoutrosblocos decondiçõesmacroeconômicasparcialmenteexógenosserão construídoseabordados separadamente: o setor externo (fluxos de comércio exterior eingresso líquido de capitais); o setor governo (gasto público ereceita deimpostos); eo setor financeiro (taxas dejuros deaplicação edeempréstimos, liquidez, condições decrédito). U ma vantagem colateral do tratamento em separado desses blocoséa maior facilidadee transparência na formulação de hipóteses de simulação envolvendo essas áreas notoriamente estratégicas para o desenvolvimento econômico, assim como na avaliação deseus efeitos.

Em suma, os aperfeiçoamentosintroduzidos consistem essencialmente(i) na montagem deum modelo bem mais detalhado esuscetível a simulações, inclusive peladisponibilidadedesoftwareadequado; e(ii) na "microfundamentação" explícita em termosdesetores/indústriasqueapresentam trajetóriasevolucionáriasem feedback com os resultadosmacroeconômicos. Em outras palavras, trata-seefetivamentede um modelo deintegração micro-macrodinâmica, em quecada um dos doisplanos tem suadinâmica específica, mas dependentedosinputsquerecebedo outro plano.

A complexidadeeo nível dedetal heem queessaintegração érealizada permitirá construir eaperfeiçoar um instrumento deanálisemicro-macrodinâmica geral que poderátambém seprestar, em especial, parasimulaçõescomparativas, sob hipóteses estilizadas, entre situações típicas de países desenvolvidos eem desenvolvimento.

\section{Conclusão}

0 esforço de integração aqui sugerido ainda está sendo esboçado. Embora sua concepção geral eestrutura básicajá estejam razoavelmentedelineadas, as etapas mais difíceis são as que se estão iniciando: de detalhamento do modelo, de sua 
programação computacional ederealização dassimulações, quedemandarão muito tempo atécompletar os testeseajustesnecessáriosa torná-lo um instrumento eficaz de análise integrada da dinâmica econômica e, particularmente, de aplicação à simulação de parâmetrose condições específicas dedesenvolvimento econômico.

As referências teóricas adotadas, neo-schumpeterianas e pós-keynesianas (incluindo Kalecki), são ambas indispensáveis a esse esforço, tanto pelo terreno comum - de racionalidade limitada, não-equilíbrio, instabilidade estrutural e dinâmica e trajetórias em aberto, quanto pela sua contribuição complementar à compreensão da dinâmica econômica - mudanças estruturais endógenase efeitos sobreo nível deatividadeinduzidos via demanda efetiva. A tentativa dearticulálos num único esquema analítico por meio de um modelo dinâmico de simulação é um desafio incomum emuito complexo, mas a perspectiva dedotar a abordagem heterodoxa da dinâmica macroeconômica de um instrumento de análise próprio, metodologicamente adequado aos seus próprios pressupostos, e potencialmente fértil deoportunidades de utilização, incluindo aquelas voltadas à investigação das especificidadesteóricas do desenvolvimento econômico, parecem suficientemente atraentes para compensar o esforço.

\section{Bibliografia}

Aghion, P. \& Howitt, P. "A M odel of Growth through Creative Destruction". Econometrica, v. 60, 1992.

Andersen, E., Evolutionary Economics. Post-Schumpeterian Contributions. London: Pinter Publisher, 1996.

Arthur, W. B., Increasing Returns and Path D ependence in the Economy. Ann Arbor: The University of M ichigan Press, 1994.

Chiaromonte, F.; D osi, G. "T he M icro Foundations of Competitiveness and their M acroeconomic Implications", 1991, in: Foray, D., Freeman, C. (eds.); Technology and the Wealth of $\mathrm{N}$ ations: the dynamics of constructed advantages. London: Pinter, 1993. 
Davidson, P., "Rational Expectations: a Fallacious Foundation to Study Crucial D ecision-M aking Processes". Journal of Post Keynesian Economics, v. 5, 1982/3.

Dosi, G., "Technological Paradigms and Technological Trajectories: a suggested interpretation of determinants and direction of technical change". Research Policy, v.11, 1982.

, Technical Change and Industrial Transformation. Londres: M acmillan, 1994.

Egidi, M., "Substantive and Procedural Uncertainty: an Exploration of Economic Behaviours in Changing Environments". Journal of Evolutionary Economics, abr., 1991.

Fabiani, S. "Convergence and Divergence in the Long-Term Growth of O pen Economies". in: Silverberg , G. \& Soete, L. (eds.), op. cit. H arrod, R., "An Essay in Dynamic Theory", Economic Journal, v. 49, 1939.

Heiner, R.,"The O rigin of Predictable Behavior". American Economic Review, v. 73, 1983.

Kalecki, M. Theory of Economic Dynamics, Londres: Allen \& Unwin, 1954.

Keynes, J. M., The General Theory of Employment, Interest and M oney. Londres: M acmillan, 1936.

Lisboa, M. B., "A M iséria da Crítica H eterodoxa" in: Revista de Economia Contemporânea, nº 2, jul./dez., 1997.

Lucas, R., Studies in Business Cycle Theory. Cambridge, M ass.: M IT Press, 1981. M insky, H ., John M aynard Keynes. N. York: Columbia University Press, 1975. N elson, R.; W inter, S., An Evolutionary Theory of Economic Change. Cambridge, M ass.: $\mathrm{H}$ arvard University Press, 1982.

Possas, M ., D inâmica eCiclo Econômico em O ligopólio. C ampinas: DEPE/U nicamp, tese de doutorado, 1983.

"U m modelo dinâmico multissetorial". Pesquisa e Planejamento Econômico, v. 14, 1984.

A Dinâmica da Economia Capitalista: uma abordagem teórica. S. Paulo: Brasiliense, 1987.

"Racionalidade e Regularidades: rumo a uma integração micromacrodinâmica". Economia e Sociedade, v. 2, ago., 1993. 
"Antecedentes e PerspectivasTeóricas da Economia do D esenvol vimento numa Abordagem Evolucionária". Revista N exos Econômicos, CM E/UFBa, v. 1 , jul., 1999a.

"D emanda Efetiva, Investimento e D inâmica: a atualidade de Kalecki para a teoria macroeconômica". Revista de Economia Contemporânea, v. 3 , jul./dez., $1999 b$.

, M., Koblitz, A., et al. , "Um M odelo Evolucionário Setorial". Revista Brasileira de Economia, v. 55 , jul./set., 2001.

Schumpeter, J. (1911). TheT heory of Economic D evelopment. Trad. inglesa, London: O xford University Press, 1934.

Silverberg, G. , "Technical Progress, Capital Accumulation and Effective D emand: a self-organization model". in: Batten, D., C asti, J., J ohansson, B., Economic Evolution and Structural Adjustment. Berlim: Springer-Verlag, 1987.

, D osi, G .; O rsenigo, L., "Innovation, Diversity and D iffusion: a selforganization model". The Economic Journal, 98, dez., 1988.

, Verspagen, B., "Learning, Innovation and Economic Growth: a Longrun Model of Industrial Dynamics". Industrial and Corporate Change, v. 3, 1994.

Simon, H., "From Substantive to Procedural Rationality". in: Hahn, F.; H ollis, M. (eds.). Philosophy and Economic Theory. Oxford: Oxford U niversity Press, 1979.

Vercelli, A., M ethodological Foundations of M acroeconomics: Keynes and Lucas. Cambridge University Press, 1991. 
